\title{
Surgical resection with adjuvant brachytherapy in soft tissue sarcoma of the extremity - a case report
}

\author{
Grzegorz Guzik, MD, PhD', Jarosław Łyczek, MD, PhD², Łukasz Kowalik, MSc² \\ IOncologic Orthopaedics Department, 2Brachytherapy Department, Hospital in Brzozów, Podkarpacki Oncology Centre, Brzozów, Poland
}

\begin{abstract}
Purpose: Surgery is the major therapeutic method in soft tissue sarcomas of the extremity (E-STS). Treatment of large high-grade tumours, which resection cannot be performed with a wide safe margin, should include complementary radiation and/or chemo-therapy. Hopefully, the use of adjuvant brachytherapy will improve the prognosis of E-STS.

Case description: After a long process of diagnosing a tumour in the medial compartment of the thigh, a 65-yearold woman with diagnosed synovial sarcoma underwent a surgery. Compartment resection was performed and the tumour was removed with a $10 \mathrm{~mm}$ safety margin of healthy tissue. Adjuvant brachytherapy was delivered with ${ }^{192} \mathrm{Ir}$ (MicroSelectron, Nucletron Electa Group, Stockholm, Sweden ${ }^{\circledR}$ ) with $10 \mathrm{Ci}$ of nominal activity to a dose of 55 Gy in 16 days because of large tumour size $(99 \times 78 \times 73 \mathrm{~mm})$ and its proximity to the neurovascular bundle. No complications were reported. The patient was discharged from the hospital on the $28^{\text {th }}$ day after the surgery. The wound healed without any complications and the outpatient follow-up is being continued.

Discussion: Adjuvant brachytherapy is rarely used after surgical treatment due to its limited accessibility in hospitals with surgical and orthopaedic departments. There are numerous publications proving positive influence of brachytherapy on local control and decreased number of recurrences. The recurrence-free survival time also increased significantly, however no direct impact on the number of distant metastases was found. Treatment is well tolerated and short. The complication rate varies between centres from 5 to $30 \%$. The most common adverse effects include: peripheral neuropathy, skin necrosis and osteonecrosis of the long bones.

Conclusions: Treatment of large soft tissue sarcomas of the extremity (E-STS) should include combination of surgical intervention and external beam radiotherapy or brachytherapy. Adjuvant brachytherapy improves local control rate up to $78 \%$, is well tolerated and rarely causes complications. We couldn't determine which type of adjuvant radiation therapy is more effective.
\end{abstract}

Key words: soft tissue sarcoma, brachytherapy, compartment surgery.

\section{Purpose}

The extremities are the most common anatomic site where soft tissue sarcomas develop i.e. almost $50 \%$ of all cases $[1,2]$. Symptoms of these malignancies are not characteristic. Usually, tumours don't cause any pain. Patients often start looking for medical help when the tumour reaches a large size. Knowledge about this type of neoplasms presented by surgeons and orthopaedists is incomplete, which often results with delays and even errors concerning diagnostic and therapeutic interventions. One should be aware that every tumour, especially fast growing ones, located beneath the fascia requires special attention and is always an indication for a diagnostic biopsy prior final surgical intervention. Diagnostic procedures should include MRI scans of the extremity with the tumour and CT scans of the lungs in order to exclude pulmonary metastases [3-7].

Surgical resection of the tumour with a safety margin of healthy tissue is the fundamental method of treatment of soft tissue sarcomas. At present, an amputation is avoided and the number of these procedures performed in soft tissue sarcomas has decreased by $20 \%$. However, an amputation is recommended in sarcomas infiltrating the neurovascular bundle and tumours causing large changes extending outside compartments where limb salvage surgery cannot preserve extremity function. Treatment should be delivered in specialist centres with multidisciplinary resources. In some cases, a complementary oncologic therapies are necessary e.g.: radiation therapy, brachytherapy and chemotherapy. Local recurrences and metastases require multidimensional approach and may be successful. The application of brachytherapy and chemotherapy seems to be associated with improved local control and the lower rate of recurrences [3-5].

At present, brachytherapy is not a standard method used for complementary treatment of soft tissue sarcoma of the extremity (E-STS) despite reports about its effectiveness.
Address for correspondence: Grzegorz Guzik, MD, PhD, Oncologic Orthopaedics Department, Hospital in Brzozów, Podkarpacki Oncology Centre, 18 ks. Bielawskiego Str., 36-200 Brzozów, Poland, phone: +48 1343 08 103, e-mail: grzegorz.guzik@vp.pl
Received: 08.12 .2012

Accepted: 14.12 .2012

Published: 23.12.2012 

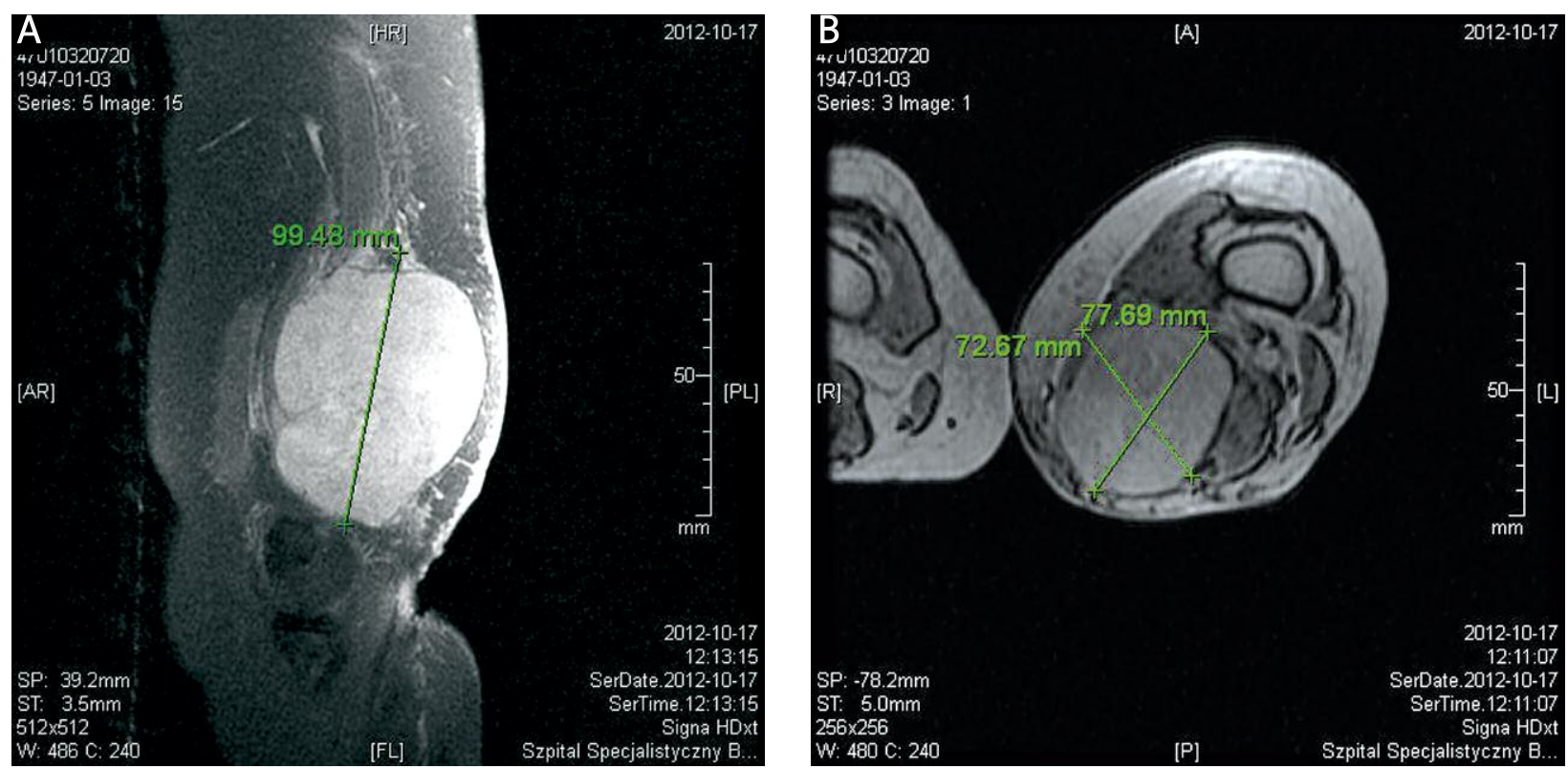

Fig. 1. MRI images of patient's left thigh revealing a large soft tissue tumour located in the medial compartment. The tumour was inhomogeneous without visible capsule and was surrounded by compressed tissues. Visible vascular modelling. Sagittal plane through the largest dimension of the tumour (A) and a cross section (B)

The biggest problem seems to be its limited accessibility and technical limitations due to the fact that brachytherapy facilities are rarely located near surgical or oncologic orthopaedic departments with the possibility of shared surgical path. Currently three types of brachytherapy are used: neoadjuvant, adjuvant and a separate treatment method in tumours which cannot be removed surgically. The application of brachytherapy as a complementary therapy in soft tissue sarcomas has a history of 30-years. For many years, due to a small number of patients, published reports were fragmentary and unequivocal as far as recommendations were concerned. At present, publications include comparisons of different brachytherapy techniques i.e. HDR (high-doserate), LDR (low-dose-rate), and a recent one - Ultra-LowDoes-Rate meaning the application of radioactive seeds [8].

Effectiveness of brachytherapy is a result of its conformality as well as imaging methods used in order to spare

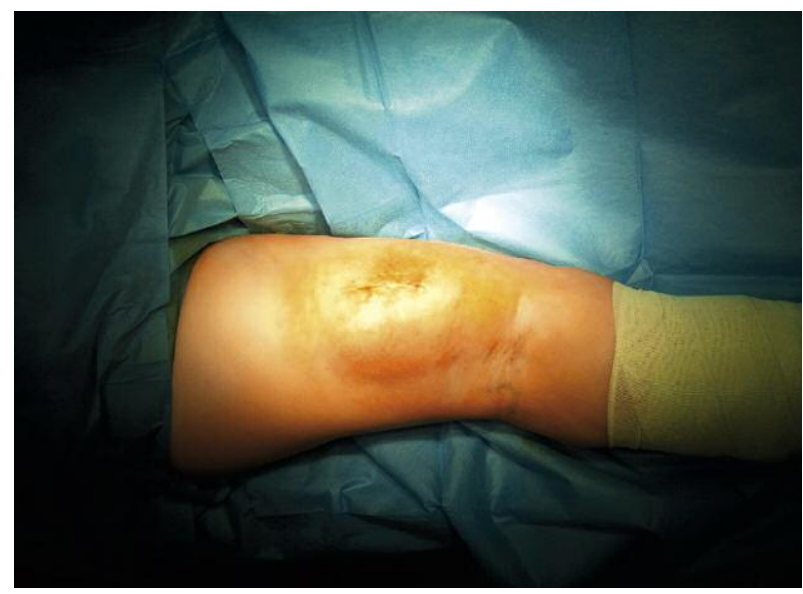

Fig. 2. A picture of a soft tissue tumour of the left thigh before the surgery. A scar after the prior biopsy is visible critical organs. The major advantage of brachytherapy is its clear influence on the increased recurrence-free five-year survival rate and better local control. The complication rate reported in different publications ranges between 5 and $32 \%$. These adverse effects concern peripheral nerves, less frequently skin, and very rarely radiation-induced muscle damage and bone loss. Few randomized trials comparing the effectiveness of brachytherapy and external beam radiation therapy didn't unambiguously indicate which method was better $[9,10]$.

\section{Case description}

A 65-year-old woman was diagnosed outside the oncology centre because of a fast growing tumour localised in the medial compartment of the left thigh. At the beginning this lesion was not painful. The patient was treated in an outpatient surgical clinic where a puncture was performed as the surgeon suspected a synovial cyst. An ultrasound examination and MRI scan revealed a tumour with radiographic features of malignancy. The tumour was growing between and infiltrating three muscles: adductor magnus, sartorius and gracilis. The large size of the malignancy $(99 \times 78 \times 73 \mathrm{~mm})$, its fast growth, increasing pain and numbness in the foot forced the need of faster diagnostics and treatment (Fig. 1).

Histopathological examination of tissue taken during the excision biopsy confirmed the suspected malignant change. Synovial sarcoma was diagnosed. The patient had a second MRI scan and the decision about limb salvage surgery was made. CT scans of the lungs and abdominal cavity didn't reveal any metastases (Fig. 2).

On October 22, 2012, compartment resection with intraoperative histopathological assessment of safety margins was performed. The whole medial compartment of the thigh muscles was removed with the tumour. No signs of infiltration 

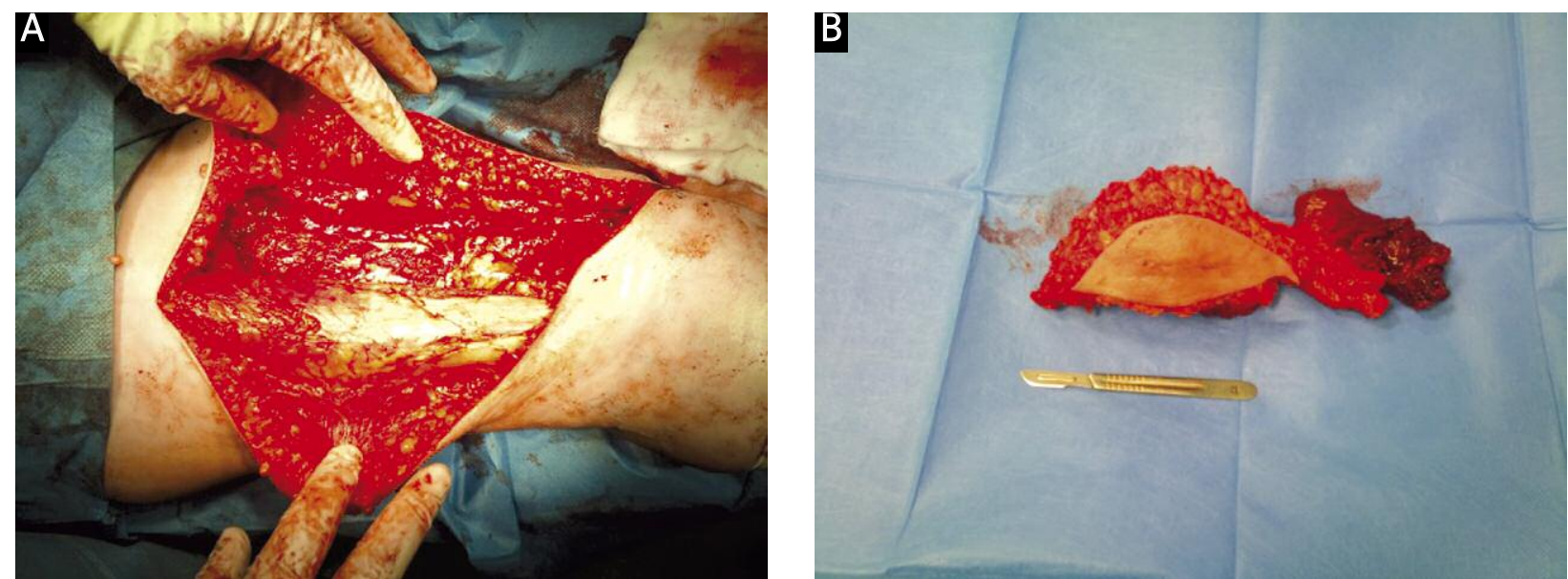

Fig. 3. The pictures of a tumour bed after resection of the neoplasm and muscle compartment (A) and the tumour with a tunnel after the biopsy (B)
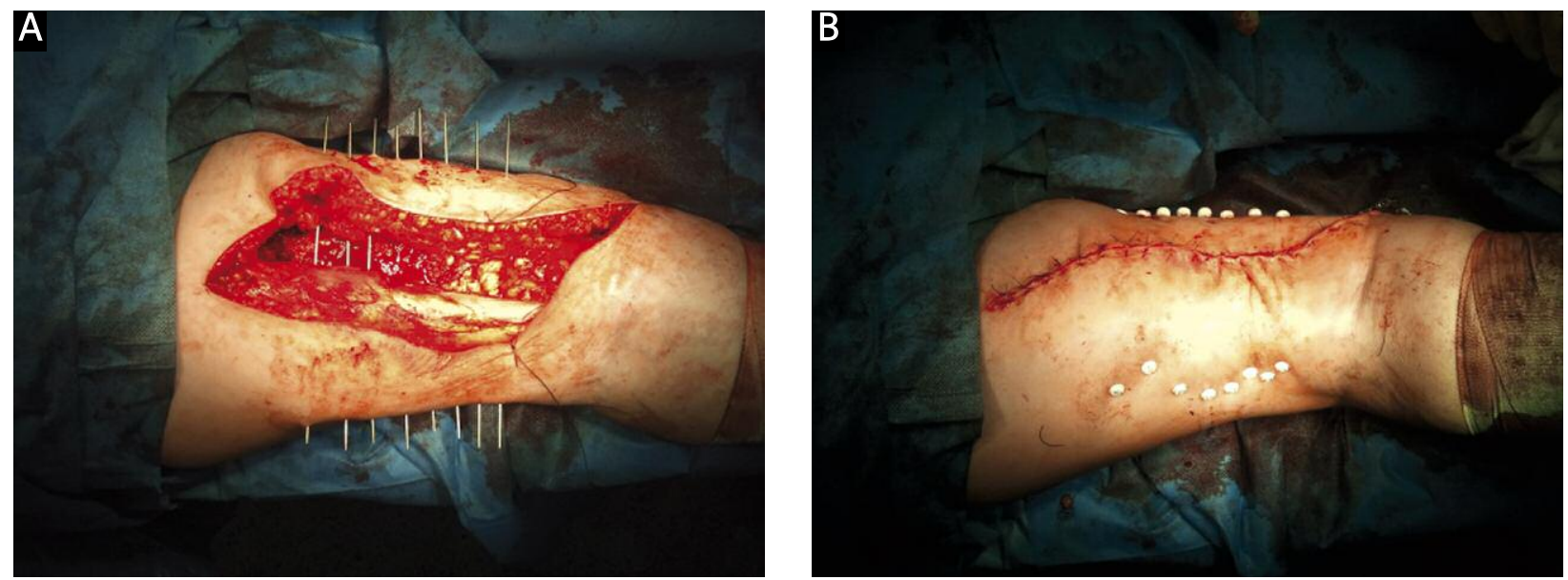

Fig. 4. The pictures presents the tumour bed in the thigh (A) and secured applicators for brachytherapy (B)

on vascular and nervous structures were found. The smallest safety margin of healthy tissue was $10 \mathrm{~mm}$ (Fig. 3).

The surgery was performed in the presence of brachytherapy specialists (radiation oncologists). After resection was finished applicators (Nucletron Elekta Group ${ }^{\circledR}$ ) were inserted under visual control. The distance between adjacent applicators was $1 \mathrm{~cm}$ whereas the proximal and distal margins vs. the tumour location in the longitudinal axis of the limb was $2 \mathrm{~cm}$. Next, the wound was closed in layers (Fig. 4).

Brachytherapy was performed using HDR technique with an 192Ir radioactive source. The first fraction was delivered during 24 hours after the surgery. Treatment planning (reconstruction) was based on CT images (GE Bright Speed $8^{\circledR}$ ) (Figs. 5 and 6). The total dose was 55 Gy (fraction dose of $2.5 \mathrm{~Gy}$ ) delivered twice a day with a minimum 6-hour inter-fraction interval. Treatment was continued for 16 days (5 days per week).

No complications were reported during the surgery as well as postoperative period and brachytherapy. Applicators were removed on the last day of radiation therapy. The wound healed by first intention. No signs of peripheral neuropathy were observed. The patient was discharged from the hospital on the $28^{\text {th }}$ day after the limb salvage surgery and is in outpatient follow-up care. We reviewed literature and found that doses delivered in similar localizations and application of HDR technique ranged between 32 and 55 Gy regardless of treatment sequence i.e. perioperative or postoperative [8]. In our case fraction dose was limited while

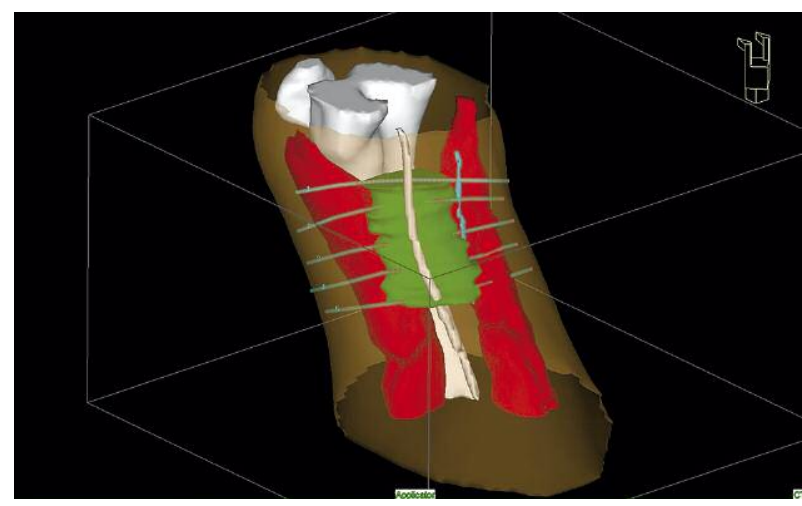

Fig. 5. 3D reconstruction of target volume (green), bone structures (white), nerve structures (blue), muscles (red) with inserted applicators 


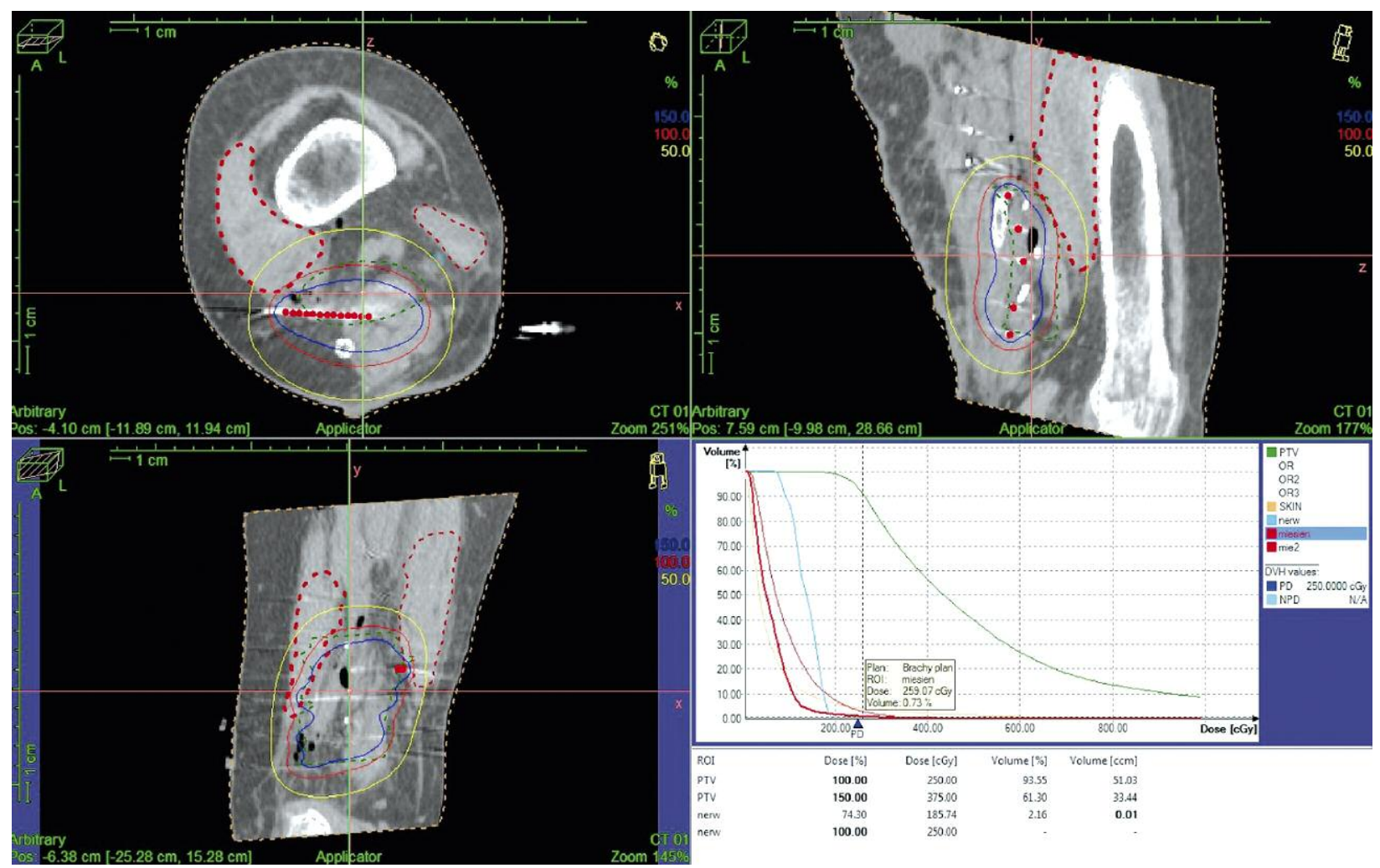

Fig. 6. Dose distribution for the target volume and organs at risk with corresponding dose volume histograms (DVH)

the total dose remained unchanged mainly due to the close proximity of femoral nerve. The presence of femoral bone seemed less important.

\section{Discussion}

Surgery is the most common treatment of soft tissue sarcomas of the extremity. It seems that $\mathrm{R} 0$ resection is the optimal solution in small tumours graded as G1 and G2. Large malignancies and those graded as G3 require resection with an adequate safety margin of soft tissue, which usually is impossible. Therefore, a complementary therapy should be delivered. The most common are neoadjuvant and adjuvant radiation therapy [5,7]. Chemotherapy in soft tissue sarcoma is usually delivered within the frames of clinical trials rather than standard treatment protocols. Researchers hope that molecular targeted therapies will solve the problem. Brachytherapy in STS is rarely administered as a therapy complementary to surgical interventions due to its technical requirements and limited accessibility [11]. It is more common in non-operable cases. The advantage of brachytherapy is the fact that applicators are inserted under visual control therefore the process is very precise and decreases the number of complications. HDR technique with ${ }^{192}$ Ir radioactive source is a standard method of dose delivery. However, recent publications report that new techniques with ${ }^{125} \mathrm{~J}$ seeds were used to deliver the dose ranging from 40 to 70 Gy [10]. Brachytherapy is well tolerated by patients. The complications rate is estimated to be around $10 \%$ and peripheral nerve damage is the major adverse effect comprising 5\% [8,10].
According to published reports, the 5-year recurrence free survival rate was 78\% [12-15]. Brachytherapy in STS significantly decreases the number of local recurrences, however it has no direct effect on the number of distant metastases. At present it is impossible to decide which type of radiation therapy is more effective, but shorter time of treatment seems to be relevant. Postoperative brachytherapy usually takes from 5 to 10 days whereas external beam radiation therapy starts from 4 to 6 weeks after the surgery. There are no clear reports indicating that teletherapy is necessary in extremity soft tissue sarcomas. Radical brachytherapy with HDR was an effective and safe treatment method.

\section{Conclusions}

Surgical treatment is the basic therapeutic method in soft tissue sarcomas of the extremity (E-STS), however delays in the diagnostic process often force the use of complementary oncologic therapy in order to maintain local control. Brachytherapy seems to be a good method of adjuvant therapy in E-STS, however its accessibility is limited. The number of complications was small. Further multicentre randomized studies should decide which method of adjuvant treatment (external beam radiation therapy vs. brachytherapy) is better and what is the optimal sequence of therapies improving local control.

\section{References}

1. Wojciechowska U, Didkowska J, Tarkowski W et al. Nowotwory złośliwe w Polsce w 2004 roku. Centrum Onkologii Instytut, Warszawa 2006 [in Polish]. 
2. Fletcher CDM, Rydholm A, Singer $S$ et al. Soft tissue tumours: Epidemiology, clinical features, histopathological typing and grading. In: Fletcher CDM., Unni KK, Mertens F (eds.). WHO Classification of Tumour. Tumours of Soft Tissue and Bone. IARC Press 2002; pp. 14-15.

3. Casali PG, Jost L, Sleijfer S et al. ESMO Guidelines Working Group. Soft tissue sarcomas: ESMO clinical recommendations for diagnosis, treatment and follow-up. Ann Oncol 2009; 20 (suppl.) 4: 132-136.

4. Ruka W. Mięsaki tkanek miękkich. In: Krzakowski M (ed.). Onkologia kliniczna. Borgis, Warszawa 2006; pp. 1153-1220 [in Polish].

5. Rutkowski P, Nowecki ZI (ed.). Mięsaki tkanek miękkich u dorosłych - monografia. Medical Tribune 2009 [in Polish].

6. Rydholm A, Gustafson P, Alvegard TA et al. Prognostic factors in soft tissue sarcoma. Acta Orthop Scand 1999; 70 (suppl. 285): 50-57.

7. Kotilingam D, Chelouche Lev D, Lazar AJF et al. Staging soft tissue sarcoma: evolution and change. CA Cancer J Clin 2006; 56: 282-291.

8. Martinez-Monge R, San JM. Perioperative HDR brachytherapy in soft tissue sarcomas of extremities \& superficial technique in adults; initial results of a pilot study. Brachytherapy 2005; 4: 264-270.

9. Livi L, Santoni R, Paiar F et al. Late treatment-related complications in 214 patients with extremity soft-tissue sarcoma treated by surgery and postoperative radiation therapy. Amer J Surg 2006; 191: 230-234.

10. Alektiar KM, Leung P, Zelefsky M. Adjuvant brachytherapy for primary high-grade soft tissue sarcomas of the extremity. Ann Surg Oncol 2002; 9: 48-56.

11. Dziewirski W, Rutkowski P, Nowecki Z et al. Surgery combined with brachytherapy in patients with retroperitoneal sarcomas. Ann Surg Oncol 2006; 13: 245-252.

12. McCarter MD, Jaques DP, Brennan MF. Randomized clinical trials in soft tissue sarcoma. Surg Oncol Clin N Am 2002; 11: 11-22.

13. O'Sullivan B, Davis AM, Turcotte R et al. Preoperative versus postoperative radiotherapy in soft-tissue sarcoma of the limbs: a randomized trial. Lancet 2002; 9325: 2235-2241.

14. Magenau JM, Schuetze SM. New targets for therapy of sarcoma. Curr Opin Oncol 2008; 20: 400-406.

15. Pisters PW, Harrison LB, Leung DH et al. Long-term results of a prospective randomized trial of adjuvant brachytherapy in soft tissue sarcoma. J Clin Oncol 1996; 14: 859-868. 